\title{
The Humanoid Biped Robot
}

\author{
Mingming Li \\ School of Mechanical Engineering,North China Electric Power University, Baoding 071000, China. \\ 969257623@qq.com,
}

\section{Keywords: Humanoid biped robot,SCM,Steering engine,Sensors}

\begin{abstract}
The development and application of industrial robots is the inevitable trend of the social development of science and technology in 21 century[1].This report mainly describes a new humanoid biped robot based on STM32 SCM and sensor system.It is characterized in that the structure is light through the mutual coordination of STM32 SCM,the sensors and the steering engines.And its functional characteristic is that the robot is able to walk by the black lines on the trick automatically without intervention,the realization of which is mainly sensors mounted on the robot and the STM32 SCM.The mounted sensor will collect information of the track and analyze it to determine the robot's current location on the track,then feedback the information to the STM32 SCM which makes the corresponding control robot to walk along the line and complete many types of action while walking,so the robot will finish the whole course effectively and accurately.
\end{abstract}

\section{Introduction}

With the continuous development of science and technology,humanity has made significant progress in many ways, in the past few centuries.As one of the greatest human invention,robot technology has been made great progress,since the 1960s,in just 40 years.

In view of the humanoid biped walk robot,The United State and Japan lead the development direction of robot,represents the highest level of science and technology in the field of robot.Robot development in our country has more than 20 years, China has listed the humanoid biped robot as the key project and give great support.Our objectives are that by adding sensor on robots to collect the information and determine the relative position of the robot,and then using the STM32 and steering gear plate to control the robot.

\section{Hardware part}

The steering gear: The robot adopts digital servo drive,this digital servo is more accurate and makes the robot movement is more agile,therefore, the robot can do some complex actions.

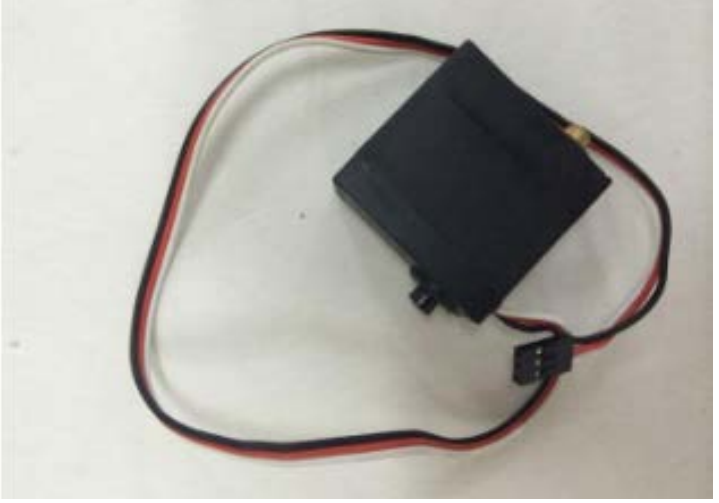

Fig. 1 The steering gear

The whole structure: The robot uses $1 \mathrm{~mm}$ thickness of hard aluminum alloy,this kind of material makes the weight of bracket is lighter . intensity is bigger and the pressure of leg ministry streering gear smaller. 


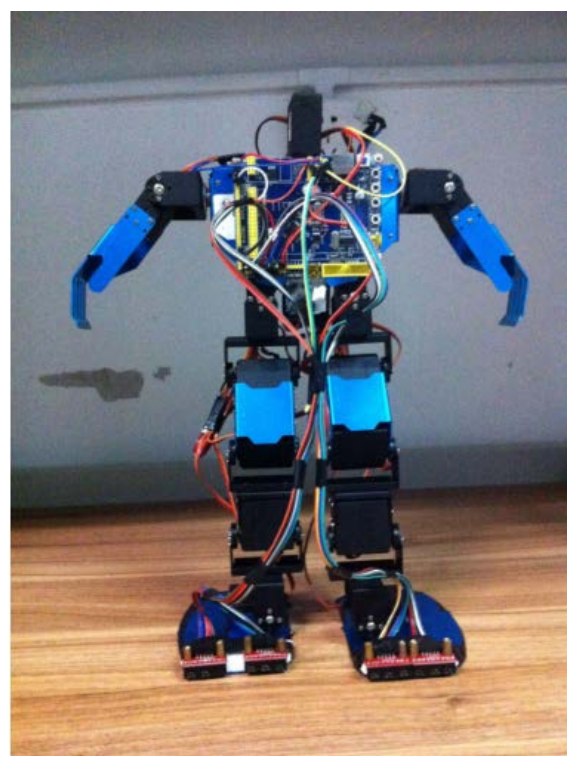

Fig. 2 The whole structure

QSC panel:Servo controller using 32 road steering gear plate and output 32 road PWM square wave to control the robot.

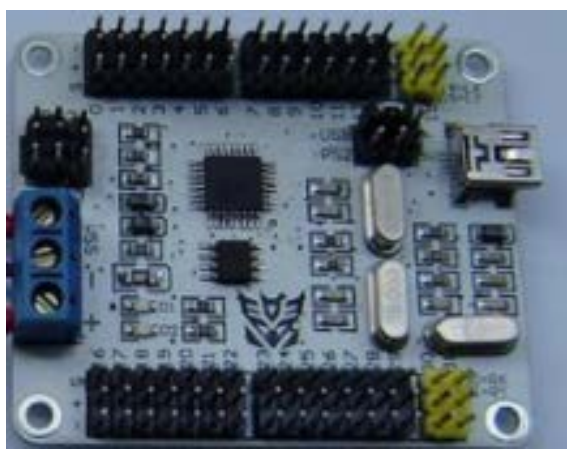

Fig.3 The QSC panel

STM32:This single chip microcomputer contains 128K FLASH,20K SRAM, two SPI,three serial,one USB,one CAN and so on[2].This single chip microcomputer run the clock frequency to $80 \mathrm{MHZ}$ and can meet the normal operation of this system date processing work.

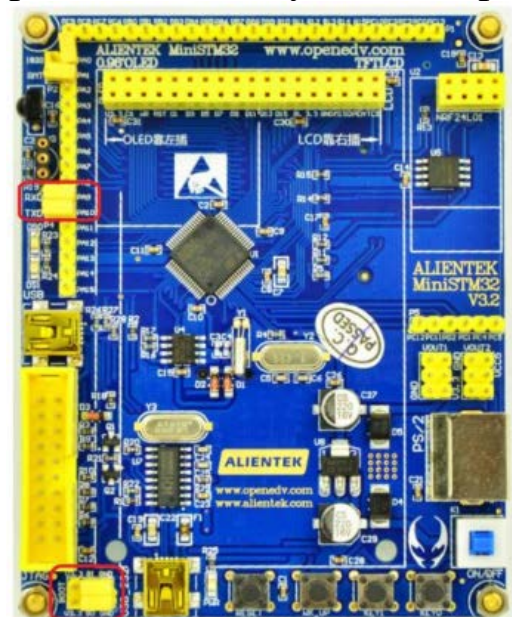

Fig.4 The single chip microcomputer

The sensor:The infrared gray sensor is the use of infrared tube detection infrared light which send by infrared transmitting tube[3].Dark reflection weak and shallow light reflex is strong[4]. 


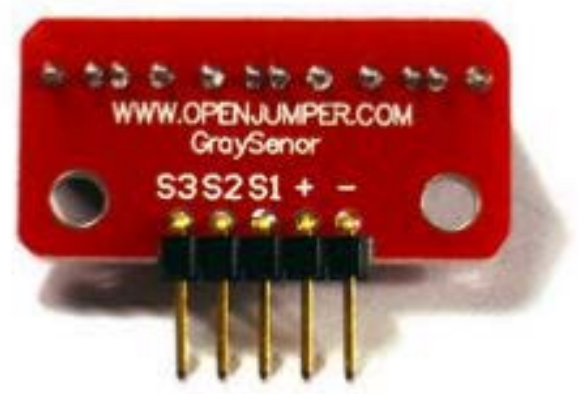

Fig.5 The sensor

\section{Software part}

STM32: The single chip microcomputer uses the keil software and C language programming.

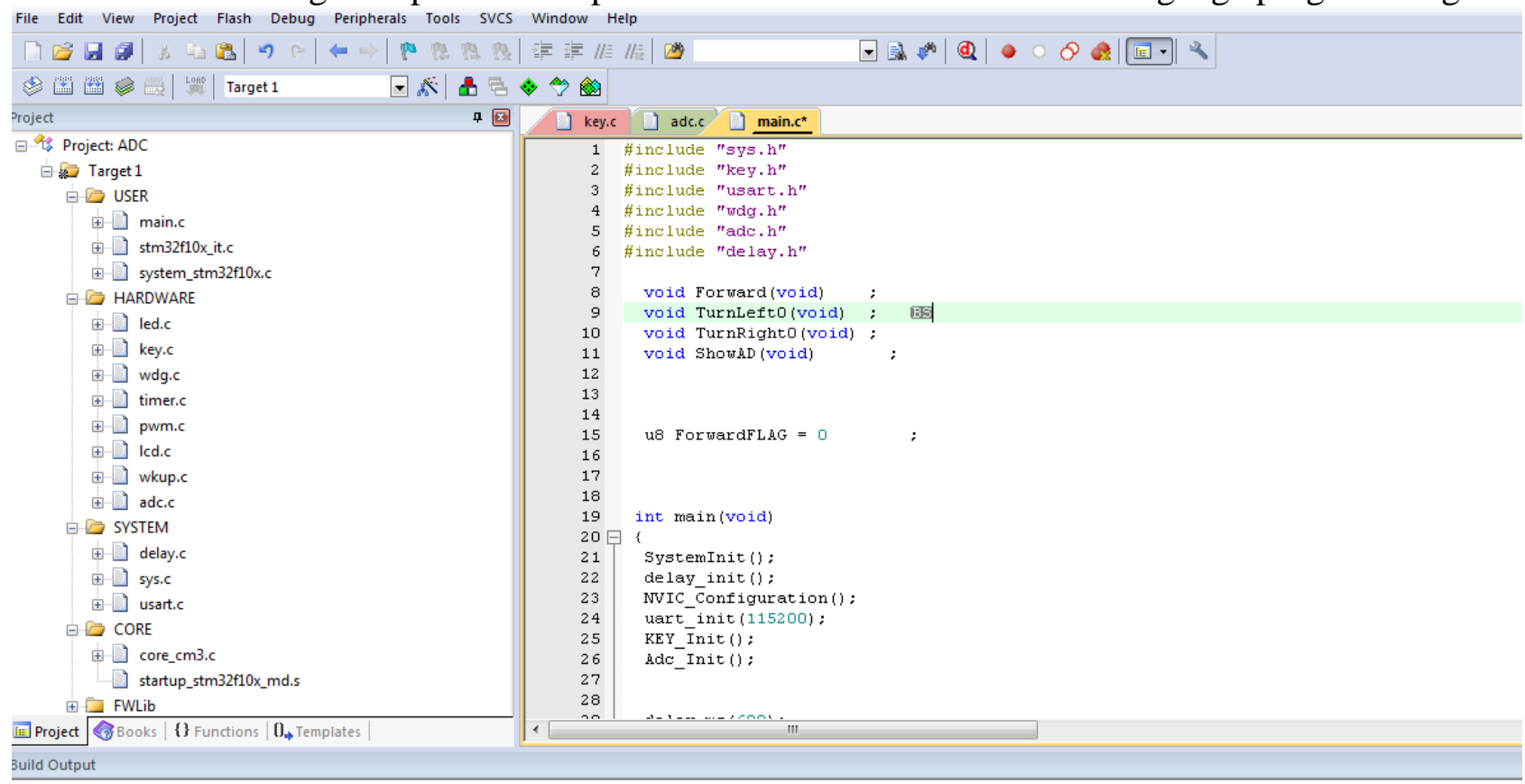

Fig.5 Software interface

Rios_usc:The action design uses the rios_usc which was 32 road steering gear plate's own software.

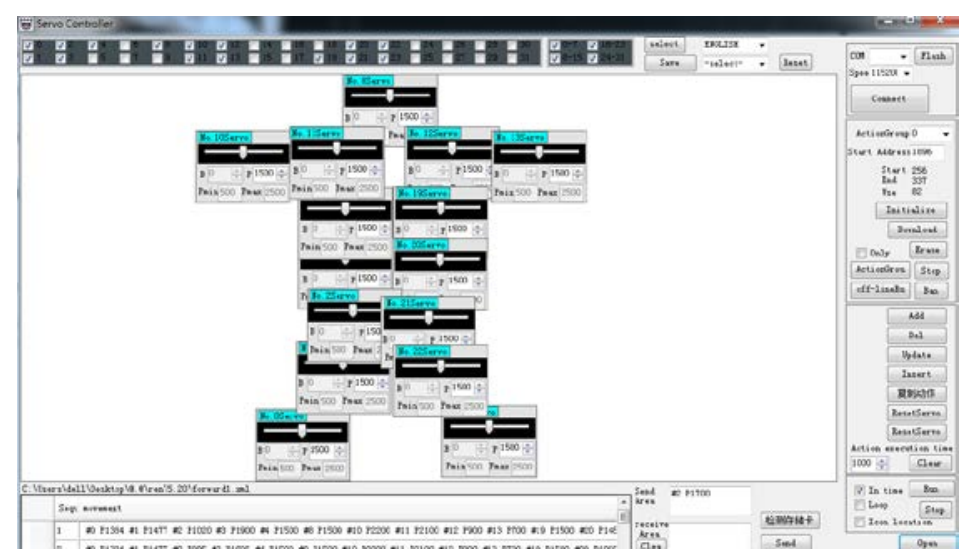

Fig.6 The action design software 


\section{Summary}

As above,this humanoid biped robot use the new train of thought.It is characterized in that the structure is light through the mutual coordination of STM32 SCM,the sensors and the steering engines.And its functional characteristic is that the robot is able to walk by the black lines on the trick automatically without intervention,the realization of which is mainly sensors mounted on the robot and the STM32 SCM.The mounted sensor will collect information of the track and analyze it to determine the robot's current location on the track,then feedback the information to the STM32 SCM which makes the corresponding control robot to walk along the line and complete many types of action while walking,so the robot will finish the whole course effectively and accurately.

After several months of effort,we have completed the assembly,programming,debugging and walking.During the period of debugging,we used several different sensors,finally,we find the one above is the best one which more stable and higher precision.

\section{Acknowledgments}

This work was financially supported by North China Electric Power University.

\section{References}

[1] Xunlin Zhu,Industrial robot technology and application,2016

[2] Guangxiang Yang, STM32 MCU principle and engineering practice, 2013.

[3] Hongping Liu,Sensor principle and application,Northwestern polytechnical university press, 2015

[4] D.A.Bernard,R,M,Owens,G.G.Malliaras,Organic semiconductors in sensor application,Peking University Press,2012 